\title{
ARQUITETURA E DECORAÇÃO ARQUITETÔNICA ROMANA: A ABORDAGEM METODOLÓGICA
}

Leonardo Fuduli ${ }^{1}$

Recebido em: 21/11/2021

Aprovado em: 29/12/2021

Resumo: Nos últimos anos, a decoração arquitetônica tem recebido mais atenção nos estudos do que no passado. Graças ao desenvolvimento de uma abordagem metodológica complexa envolvendo diferentes áreas das ciências da antiguidade, foi possível desenvolver o potencial científico resultante deste valioso fragmento do passado, foi possível desenvolver o potencial científico resultante desta valiosa descoberta do passado, através da análise dos mármores que o compõem e do cálculo dos custos de construção. Neste artigo serão analisadas as principais metodologias aplicadas à decoração arquitetônica, juntamente com um percurso diacrónico do seu desenvolvimento.

Palavras-chave: Metodologia; arquitetura; decoração arquitetônica; Roma; história da investigação

\section{ARQUITECTURA Y DECORACIÓN ARQUITECTÓNICA ROMANA: EL ENFOQUE METODOLÓGICO}

Resumen: En los últimos años, la decoración arquitectónica ha recibido más atención en los estudios que en el pasado. Gracias al desarrollo de un enfoque metodológico complejo que involucra diferentes áreas de las ciencias antiguas, fue posible desarrollar el potencial científico resultante de este valioso fragmento del pasado, fue posible desarrollar el potencial científico resultante de este valioso descubrimiento del pasado, mediante el análisis de los mármoles que lo componen y el cálculo de los costos de construcción. En este artículo se analizarán las principales metodologías aplicadas a la decoración arquitectónica y un recorrido diacrónico de su desarrollo.

Palabras clave: Metodología; arquitectura; decoración arquitectónica; Granada; historia de la investigación

\section{ROMAN ARCHITECTURE AND ARCHITECTURAL DECORATION: THE METHODOLOGICAL APPROACH}

\footnotetext{
1 Doutor em Arqueologia pela Università degli Studi di Messina (UNIME-Itália). Funcionário docente do Ministero dell'Istruzione dell'Università e della Ricerca (MIUR-Itália). Membro do Laboratório de Estudos sobre a cidade antiga (Labeca/MAE/USP). E-mail: leonardo.fuduli@usp.br Orcid: https://orcid.org/0000-0002-17311732.
} 
Abstract: In recent years, architectural decoration has received more attention than in the past. Thanks to the development of a complex methodological approach involving different areas of ancient sciences, it was possible to develop the scientific potential resulting from this valuable fragment of the past, through the analysis of the marbles that compose it and the calculation of construction costs. In this article, the main methodologies applied to architectural decoration will be analyzed, along with a diachronic path of its development.

Keywords: Methodology; architecture; architectural decoration; Roma; history of research.

O objetivo deste artigo é destacar, por meio de um caminho diacrônico de estudos, quais são as metodologias para abordar corretamente o estudo da decoração arquitetônica em edifícios antigos, com particular atenção à era imperial. A decoração arquitetônica refere-se aos elementos esculpidos em pedra, mas especialmente em mármore, feitos para decorar um edifício antigo. Hoje isto sobrevive em alguns casos de sorte ainda in situ, mas na maioria dos casos na forma de desiecta membra em sítios arqueológicos, museus e depósitos. Se estudados, esses fragmentos contêm muitos dados que podem aumentar nosso conhecimento do mundo antigo de muitas maneiras. A importância deste estudo é evidenciada pelo fato de que nos últimos anos tem sido dedicada a este tema numeroso estudos e congressos e sites internet ${ }^{2}$.

As razões são muitas, mas a principal delas é que a decoração não é o resultado do caso. Pelo contrário, é resultado de escolhas precisas. Uma vez que os estudiosos compreenderam isso, muitas possibilidades promissoras para a investigação científica foram abertas, principalmente na Itália, na Alemanha, na França e mais recentemente nos Estados Unidos. O primeiro nível de análise, que é também o mais tradicional, é estilístico.

Após uma fase, correspondente à era republicana, em que se desenvolveu um estilo fortemente influenciado pela arte helenística, na era imperial especialmente de Augusto em diante o estilo é determinado e, muitas vezes imposto, pelo Imperador e nem sempre sobrevive a ele.

Com Augusto se inaugura o classicismo a base ática, cuja forte influência é exercida não apenas no contexto provincial, através do envio de protótipos a serem imitados, mas também em períodos posteriores (Pensabene, 1982, p. 119-120; 2015, p. 822-823). As épocas posteriores são caracterizadas por manifestações de reação ao classicismo, como no período flaviano, ou revisitando, tais como na época entre os imperadores Trajano e Adriano, quando um classicismo, que lembra o estilo de Augusto foi estabelecido na arquitetura oficial. Então a decoração tem um significado ideológico forte que foi percebido pelas pessoas que no dia a dia

\footnotetext{
${ }^{2}$ Para um primeiro contato com este estudo, pode ser útil visitar o site italiano editado por Marina Milella: https://www.decarch.it/wiki/index.php/Pagina_principale.
} 
frequentavam os edifícios antigos. Portanto, é claro que a decoração arquitetônica tem um significado ideológico que vai muito além da forma, muito mais profundo, com o objetivo de comunicar a observadores e visitantes de um edifício as escolhas desejadas pelo príncipe.

Um outro nível de análise diz respeito ao material utilizado, ou seja, o uso de mármore, o seu principal material. Isso abre muitas linhas de pesquisa sobre a origem dos mármores, os preços, as pedreiras imperiais, as rotas de comércio, os naufrágios. Estes dados permitem aprofundar a história econômica do império, o que faz com que não seja apenas um discurso estilístico, que também é muito importante (Russel, 2013; Toma, 2020). Definir a origem dos mármores é útil para: identificar a oficina de produção, reconstruir a história do mármore, traçar rotas comerciais, identificar fontes alternativas de fornecimento de mármore substituto para cópias e restaurações.

O reconhecimento autóptico do mármore é muito difícil e, na maioria dos casos, deve ser abordado com base na arqueometria. Richard Lepsius (1810-1884) foi o primeiro que amostrou e visitou as mais importantes pedreiras gregas antigas e com as suas análises conseguiu identificar com precisão o mármore de importantes esculturas arcaicas e clássicas gregas de Atenas. Ainda não existe um método para identificar mármores que não seja destrutivo ou que seja suficiente para chegar a um resultado com um conteúdo de alta probabilidade através da análise de uma pequena amostra.

Para ter maior confiabilidade, é necessário combinar múltiplos métodos de análise: lâmina delgada, ou seja, uma preparação laboratorial de uma amostra de rocha, mineral ou solo para observação com microscópio petrográfico; catodoluminescência; spin eletrônico; análise de isótopos estáveis de carbono e oxigênio. Os dados obtidos são comparados com um banco de dados construído analisando um grande número de amostras de mármore de referência retiradas em antigas pedreiras (Lazzerini, 2004).

Além da análise do fragmento individual, é essencial, quando conhecido, analisar o contexto arqueológico. A decoração é muito importante para reconstruir a história edilícia de uma cidade, especialmente onde os monumentos foram destruídos por causa do desenvolvimento urbano de idades posteriores. Existem muitos casos e encontramos um exemplo no caso das cidades de Como e Parma no Norte da Itália, onde os estudos de Maria Pia Rossignani e Furio Sacchi permitiram a reconstrução dos monumentos antigos, até então conhecidos apenas pelas fontes literárias, somente pela análise da decoração existente (Rossignani, 1975; Sacchi, 2012).

Uma particularidade da decoração arquitetônica é que ela com muita frequência sobrevive à destruição dos monumentos antigos. Na verdade, ela é removida, em primeiro lugar, 
no momento do despojamento dos edifícios antigos, tornando-se spolium (spolia no plural). O fenômeno do reaproveitamento dos materiais arquitetônicos antigos, muitas vezes sem considerar a função original desses, aparece devido a alguns fatores de poupança, especialmente em Roma na época medieval (Pensabene, 2015), e ao desejo de se reconectar para a grandeza imperial do passado, como em Sicília durante a dominação normanda (Fuduli, 2018; 2020). Os elementos reaproveitados além da originária função deles, tem, portanto, uma segunda história que pode ser estudada através da análise da forma e das molduras.

Resumindo, estudando a decoração arquitetônica romana pode-se obter resultados: sobre a estrutura, o aspecto e o significado de um edifício antigo portanto, também sobre a percepção dos usuários; dados não apenas sobre a evolução do gosto mas também sobre a cronologia; informações econômicas sobre a origem do mármore e o custo do edifício.

O desenvolvimento desta abordagem metodológica abrangente deve ser analisado em seu caminho evolutivo diacrônico. Por esta razão, parece útil fornecer uma história dos estudos sobre decoração arquitetônica repercorrendo as etapas mais significativas.

Um dos primeiros estudos de decoração arquitetônica foi o de Edmund Weigand (1914), que entendeu que não necessariamente cada forma decorativa seguia a anterior em um caminho evolutivo. Isto o levou a reconhecer as diferentes peculiaridades nos modos de expressão entre os impérios romanos oriental e ocidental, tentando traçar a constituição, tanto em Roma como no Oriente, da tipologia das formas decorativas, que também se estendeu às províncias. Ele reconheceu a função de guia das capitais coríntias, nas quais variações foram introduzidas lentamente em uma estrutura que tinha sido mais ou menos a mesma desde o período helenístico.

Foi precisamente sobre os capitéis coríntios que dois estudos se concentraram e lançaram as bases para análises posteriores: o primeiro por Margarete Gütschow (1921), que tratou da origem do capitel normal ou ocidental de Corinto desde seu surgimento na Grécia até sua introdução em Roma; o outro por Richard Delbrück (1907-1912) que estudou a arquitetura helenística do Latium e identificou suas características fundamentais.

Foi Heinz Kähler (1939), que estudou os capitéis encontrados nas localidades romanas ao longo das beiras do Reno, que estabeleceu uma metodologia para o estudo dos capitéis, focalizando a relação entre Roma e as províncias. Ele determinou uma sequência cronológica precisa para o início da era imperial, definindo as características dos capitéis do final da república e do início de agosto e, em particular, identificando um grupo com características específicas produzidas durante o período do segundo triunvirato. Um estudo de fundamental importância é o estudo de Edmund Strong sobre a decoração arquitetônica do período de 
Trajano e Adriano, identificando sua origem augustea e seu caminho evolutivo com contribuições orientais.

Nos últimos cinquenta anos, duas tendências podem ser discernidas nos estudos: uma tendência analítica liderada por estudiosos alemães e uma tendência socioeconômica liderada por estudiosos italianos e franceses.

A abordagem analítica envolve um estudo tipológico e estilístico dos materiais em seu aspecto evolutivo. Os principais estudos são os de Wolf Dieter Heilmeyer (1970), que estuda a evolução da chamada capital "normal" de Corinto na Itália, Grécia e Oriente, analisando exemplares de contextos datados, e o de Christoph Friedrich Leon (1971) no Fórum de Trajano, que não só analisa a decoração arquitetônica do monumento, mas também os fragmentos que constituem seus precedentes e a formação de trabalhadores que trabalharam em outros monumentos.

A abordagem socioeconômica da decoração arquitetônica inclui um foco no contexto do edifício e, em particular, na restauração do edifício, como se pretendia que fosse percebido por seus usuários. Esta tendência inclui os numerosos estudos de Patrizio Pensabene (1973; 1982; 2000; 2005), assim como os de Giovanna Cavalieri Manasse (1978) e Pierre Gros (1979).

As duas abordagens metodológicas não se excluem mutuamente, mas precisam ser adotadas de forma complementar. A abordagem analítica continua sendo um método fundamental; na maioria dos casos os elementos arquitetônicos decorados não têm mais um contexto arqueológico ou não provêm de uma escavação arqueológica. Neste caso, é o único método que permite o enquadramento estilístico e a datação.

Atualmente, a visão formalista herdada da história da arte está sendo superada e novos instrumentos de análise foram introduzidos, como: o conhecimento dos materiais; a análise das técnicas de trabalho; o contexto histórico e o significado do encontro entre fabricante e cliente; o significado iconográfico. Todos estes elementos que proporcionam uma leitura abrangente dos dados podem ser encapsulados em uma definição recentemente utilizada por Patrizio Pensabene, a saber, a leitura semântica (Pensabene, 2017, p. 13-17). Isto envolve: o reconhecimento da moldura à qual ela pertence; a análise tipológica e cronológica; a compreensão da posição no edifício, mesmo que as informações sobre a proveniência não sejam mais conhecidas.

Para completar o quadro das metodologias em uso no campo da decoração arquitetônica, deve ser feita referência a sua consideração como uma expressão de luxo e prestígio e como ferramenta de propaganda e celebração do poder, distinguindo sua função nas esferas pública e privada (Von Hesberg, 1988, P. 185-193; 1992, p. 125-147). 
Este importante aspecto ainda é um dos menos desenvolvidos dentro das novas abordagens metodológicas e, envolvendo a percepção dos usuários do edifício em diferentes níveis, ele tem aspectos interdisciplinares que estão apenas começando a ser explorados. Esta percepção ou entendimento pode ocorrer a partir do que está estratificado na experiência de arquitetura e decoração do espectador. O tipo arquitetônico foi imitado, repetido, alterado, mas na mente do observador é sempre referenciado a um tipo comum.

A partir desta breve visão geral, fica claro que a análise da decoração arquitetônica, para ser frutífera do ponto de vista científico, deve ser feita em vários níveis, cada um dos quais apresenta sua própria complexidade. Somente analisando a soma de todos os dados será possível dizer que desenvolvemos todo o potencial desses materiais preciosos a fim de reconstruir partes importantes da paisagem antiga.

\section{Referências Bibliográficas}

AMY, Robert; GROS, Pierre. La Maison Carrée de Nîmes. Paris: Édition du C.N.R.S., 1979 [Gallia, supplèment XXXVIII ${ }^{\mathrm{e}}$ ]

CAVALIERI MANASSE, Giuliana. La decorazione architettonica romana di Aquileia, Trieste e Pola. 1. L'età repubblicana, augustea e giulio-claudia. Padova: Associazione Nazionale per Aquileia, 1978.

DELBRÜCK, Richard. Hellenistische Bauten in Latium I-II. Strassburg: Strassburg, K.J. Trübner, 1907-1912.

GÜTSCHOW, Margarete. Untersuchungen zum korinthischen Kapitelle. Jahrbuch des Deutschen Archäologischen Instituts, v. 36, p. 44-83, 1921.

HEILMEYER, Wolf-Dieter. Korintische Normalkapitelle. Studien zur Geschichte der römischen Architekturdekoration. Römische Mitteilungen, suppl. 16, 1970, 11.

KÄHLER, Heinz. Die römischen Kapitelle des Rheingebietes. Berlin: Verlag von Walter de Gruyter, 1939.

LEON, Christof. Die Bauornamentik des Trajansforum und ihre Stellung in der früh-und mittelkaiserzeitlichen Architekturdekoration. Rom Wien-Köln-Gratz, 1971.

PENSABENE, Patrizio. Scavi di Ostia. Vol. VII, I capitelli. Roma: Istituto Poligrafico dello Stato, 1973.

PENSABENE, Patrizio. La decorazione architettonica di Cherchel: cornici, architravi, soffitti, basi e pilastri. In: 150-Jahr-Feier Deutsches Archäelogisches Institut Rom; Ansprachen und Vorträge. 4.-7. Dezember 1979, Römische Mitteilungen 25, Mainz, pp. 116-169, 1982.

PENSABENE, Patrizio. Marmi e architettura nel teatro di Taormina. In: Un ponte fra l'Italia e la Grecia. Atti del simposio in onore di Antonino Di Vita, Ragusa 13-15 febbraio 1998, Padova. p. 213-255, 2000.

PENSABENE, Patrizio. La decorazione architettonica del teatro di Catania. In: МЕГААI NE OI. Studi dedicati a Giovanni Rizza per il suo ottantesimo compleanno, 2, Palermo. p. 187-212, 2005.

PENSABENE, Patrizio. Per un superamento dell'approccio tipologico alla decorazione architettonica. In: PENSABENE, Patrizio; MILELLA, Marina; CAPRIOLI, Francesca (Eds.). 
Decor. Decorazione e architettura nel mondo romano. Atti del convegno internazionale. Roma, 21-24 maggio 2014 (Roma), 2018, p. 13-17.

STRONG, Donald Emrys. Late Hadrianic Architectural Ornament in Rome. British School at Rome. Papers, v. 21, p. 118-151, 1953.

VON HESBERG, Henner. Publica magnificentia. Eine antiklassizistische Intention der frühen augusteischen Baukunst. Jahrbuch des deutschen archäologischen instituts, v. 107, p. 125147, 1992.

VON HESBERG, Henner. Architekturkopien. Eine Form von Rechtfertigung der Luxuria private. In: Bathron. Beiträge zur Architektur und verwandten Künsten fürHeinrich Drerup zu seinem 80. Geburtstag von seinen Schülern und Freunden, Saarbrücken, 1988, p. 185-193.

WEIGAND, T. Baalbek und Rom. Berlin, 1914.

\section{Fontes Web}

MILELLA, M.: https://www.decarch.it/wiki/index.php/Studi_/Storia_degli_studi\#cite_note11. Acesso em: 30/11/2021. 